\title{
Integration of intercultural values into learning a foreign language as a method of intensifying the educational process
}

\author{
Anzhelika Gadakchyan ${ }^{1}$, Nina Kapitonova ${ }^{1,{ }^{*}, \text { Anastasia Rudometova }}{ }^{1}$, and Anna \\ Temirbulatova ${ }^{1}$ \\ ${ }^{1}$ Don State Technical University, 344003, Gagarin Square, 1, Rostov-on-Don, Russia
}

\begin{abstract}
This article deals with the necessity of integration of intercultural values into learning a foreign language. Urgency of the research is defined by new claims and progression in education and also the necessity to optimize the educational process and increase its movement through the help of promotion of intercultural values into the educational process. The aim of the article is supporting a person with cultural self-actualization during the learning process of a foreign language and also increasing his/her self-motivation. In the article the question about using axiological approach is set up with the purpose of intensification of the educational process. The research was held with the help of analytic and axiomatic methods. The result of the research presented in this article is the conclusion that intensification of the educational process via integration in it intercultural values in all steps of education is important factor for achieving professional skills under the conditions of globalization and information technology in education. It will also provide a continuous mass exchange of experience of different nationalities and countries, it will give a great stimulus to social and technical progress and will also help to decide a lot of human problems.
\end{abstract}

\section{Introduction}

The globalization of the educational process, as an integral aspect of the informatization of society, has led to the need to popularize professional education. Key aspects of globalization, such as the integration of the educational process with the help of using new methods and technologies, the value of the knowledge gained, the increasing role of lifelong learning, were catalysts for innovations in the field of professional education, as well as to substantiate new requirements for the educational process. The mobility of modern society, new providers of education, the need to increase the volume of acquired knowledge in a short period of time without losing their relevance, have led to significant changes in the principles and methods of education and upbringing, as well as to the indispensable need for additional intensification of the learning process.

\footnotetext{
* Corresponding author: neonilak@inbox.ru
} 
New requirements put forward to the learning process include many aspects, such as expanding the ways of transferring and receiving cultural and social experience, orientation towards universal human values, as well as the integration of national and world values. These aspects are especially relevant when teaching a foreign language, since the study of a foreign culture and values is an integral part of the organization of the process. As a result, the trend towards the use of the axiological approach in education, which has become widespread in the last decades of the last century, does not lose its relevance, but, on the contrary, generates an increasing need for an in-depth study of the cultural values of the peoples of the world for a productive dialogue that does not imply social or ethnic inequality, as the nature of international cooperation in the modern world is complicated by political, cultural, general social and other factors influencing the relationship between representatives of different cultures, which determines the changed role of intercultural dialogue.

Scientific and technological progress, informatization, global problems, and as a result, the reorganization of education, coupled with the rapidly changing needs of modern society, entailed not only the need to intensify learning in order to accelerate the pace of perception of new information and the development of new skills, but also the integration of cultural values into all aspects of social, political and international relations.

\section{Globalization of education and its impact}

Education, as one of the integral aspects of social life, has always been a flexible process that adapts to the constantly changing needs of human society. World informatization and technological progress, the ubiquitous spread of means of communication and the rigoric competition of civilization models led to a change in the group consciousness of humanity, which in turn led to the entry of education into the stage of radical reforms.

Modern education puts forward a wide range of requirements, such as a focus on the allround holistic development of the individual in accordance with his needs and personal qualities, the transduction of educational activity into educational and cognitive, the humanization of education, its continuity, as well as mass character and openness. Education within a single state is an indispensable condition for the high-quality and intensive development of the economy and social environment, which determines new mandatory requirements for the qualifications and knowledge of a modern specialist, the need for continuous training, improving skills and professional retraining. The openness of the world educational models allows the joint use of the knowledge and intellectual capabilities available in the arsenal of mankind, access to all sources of information necessary for professional and personal development.

Informatization of society has become one of the key elements of globalization. The globalization of education provides a continuous exchange of information, resources, technologies, as well as the possibility of using the experience accumulated by mankind to improve skills at various levels of professional training.

"The globalization of education is a process of increasing adaptation of the education system to the needs of the global market economy" [1]. Modern principles of organizing the training system call for the maximum use of all available resources, rationalize the structure of educational programs, revise standards, and also strongly motivate the individual for social, cultural and intellectual development. The rapid growth rate of the necessary knowledge determines not only the need for drastic changes in the principles and methods of modern education, as well as an increase in the efficiency of joint use of intellectual resources, but also the creation and synthesis of global social and cultural values. 
For the successful process of globalization of education, the use of all the advantages of the international integration of educational phenomena, it is necessary to create positive conducive conditions for intercultural interaction and cooperation, recognition of national differences, as well as encouragement of positive intercultural contact and the development of international relations. Thus, the process of globalization puts forward increased requirements for specialists in the field of linguistics and intercultural communication, as direct mediators in international interaction.

\section{Problems of intercultural communication}

According to a number of scientists, the globalization of education inevitably leads to a number of shortcomings in the development of modern society (see Table 1.). The negative consequences include the rapidly growing discrepancy between the levels of development of various peoples, the legitimate possibilities of a number of countries for the use of intellectual resources, the potential probability of the destruction of a number of civilizations and peoples, which together provoke conflict situations within the framework of intercultural dialogue. The growing scale of cultural borrowing of developing regions from developed ones can also be attributed to the negative consequences of globalization [2].

Table 1. Advantages and disadvantages of the development of modern society.

\begin{tabular}{|l|l|}
\hline Advantages & Disadvantages \\
\hline Creation of a unified educational space & Weakening of the national sovereignty of states \\
\hline Worldwide availability of education & Phased destruction of the national color \\
\hline $\begin{array}{l}\text { Free access to the knowledge accumulated by } \\
\text { humanity }\end{array}$ & $\begin{array}{l}\text { The discrepancy between the levels of } \\
\text { development of countries and peoples }\end{array}$ \\
\hline Continuous and peer learning opportunities & Potential extinction of a number of peoples \\
\hline Opportunity to exchange practical experience & $\begin{array}{l}\text { Extensive cultural borrowing to the detriment of } \\
\text { ethnic characteristics of peoples }\end{array}$ \\
\hline Collaboration capability & The ability to create a global language \\
\hline Raising the profile of selected global organizations & Practical uneven distribution of benefits \\
\hline $\begin{array}{l}\text { Improving the quality and speed of scientific and } \\
\text { technological progress }\end{array}$ & \\
\hline Increase in labor productivity & \\
\hline $\begin{array}{l}\text { Transnationalization and recognition of cultures of } \\
\text { small peoples }\end{array}$ & \\
\hline $\begin{array}{l}\text { Creating shared values that can positively influence } \\
\text { global problems }\end{array}$ & \\
\hline
\end{tabular}

The process of globalization cannot be considered complete, which means that its consequences are potential. Possible results are quite ambiguous, for example, the process of globalization can both improve the situation of small ethnic groups and provoke their assimilation or disappearance.

Previously, the implicative tendencies of some nationalities to exalt their cultural values over others are becoming more and more obvious, which can subsequently lead to cultural expansion. As a result, there is a weakening of national states, the worldwide monopolization of individual organizations and companies. The incompetence of the mediators of intercultural communication aggravates the situation, provoking international conflicts. Thus, the need to improve the quality of intercultural communication is becoming more acute in order to avoid the manifestation of stereotypical models of behavior, violation of etiquette norms of representatives of another culture, religious conflicts and other acute problems of modern society.

At the same time, we can talk about high scientific and technological progress, adapting to itself the characteristics of intercultural contact, the direct condition of which is tolerance 
and mutual understanding of communicative partners. A participant in intercultural communication must have an idea and adequately perceive the national mentality of the partner, as well as take into account his vision of the picture of the world, then in the process of communication the participants have the opportunity to choose a style of behavior that ensures the success of mutual understanding without losing their own national identity. Thus, we can talk about a certain fusion of cultural characteristics of communicative partners, smoothing out stereotypes and a partial confusion of national mentality.

The range and intensity of international contacts determine the urgent need to revise and rethink the features of intercultural communication, interpret the elements of the vision of the world and the mentality of individual peoples and a deeper understanding of cultural values in order to generalize their characteristics and integrate them into intercultural communication.

The derivation of generalized world values allows us to talk about the elevation of intercultural communication to a new level, allowing for productive contacts that contribute to a healthy globalization of all spheres of human relationships. It is cultural values, generalized for the world society, that make it possible to combine the political, technological, social and other spheres as a way to overcome the global crisis. Such a change in paradigm foundations brought cultural studies into the status of a self-sufficient scientific discipline that has a direct connection with all aspects of social reality.

Thus, education in the period of globalization is not only a process of gaining knowledge and experience for students, but also cognition and familiarization with the cultural layers of human society, global values, which determines and deepens knowledge of specific competencies in various cultural situations, stimulates the formation of professional self-awareness within the framework of global space.

The idea of cultural reorientation is especially relevant as a tool for influencing the consciousness of the student in order to develop the skills of living in a rapidly developing multicultural and multilingual world space.

\section{Integration of intercultural values through the application of the acseological approach in learning}

In modern linguistics and methods of teaching foreign languages, it becomes impossible to achieve the unitarity of the educational process without the global integration of the material and spiritual culture of various countries, which stimulates the intensive expansion of the spheres of intercultural communication of members of the world community, deepening the content of their cooperation. Intensive internationalization and integration of various aspects of the life of states have made the role of foreign languages as a means of intercultural communication the most significant [3]. This approach gives the student a broad understanding of the ways of formation of linguistic realities, ethnography, etymology of linguistic units and other aspects of linguistic reality and worldview. The sociocultural approach appears to be a tool for identifying cultural differences, determining ways to overcome them and ensuring a productive intercultural dialogue. In addition to studying the traditions and national customs of an ethnos, individuals learn historically conditioned realities, unequal vocabulary, basic knowledge about the formation of the structure of a modern language, which in turn makes it possible to overcome ethnocentrism in a modern multiethnic society. The modern Federal State Educational Standard of the Russian Federation considers the skill of the communicative ability of positive intercultural communication as a universal competence, indispensable for any direction of professional training. 
The integration of intercultural values in the study of a foreign language is an integral part of the educational process. Language is not only a sign system that allows one to express thoughts, feelings, emotions, but also a significant resource for learning the culture of other peoples. Spiritual values are very easy to grasp and accept through words. A separate language system generates a certain image of the world among its owners, which is evidenced by the constantly arising difficulties in communicating between people belonging to different cultures and, especially when translating from one language into another. Often people use in their speech well-established expressions, slangisms, sayings that are passed down from generation to generation and it becomes impossible for a recipient who speaks the language but does not know the cultural characteristics of the speakers to understand the essence of the conversation.

The axeological approach in the pedagogical paradigm allows not only to preserve the national self-consciousness of a particular people, but also to give an idea of the ethnic picture of the world of the people-partner of intercultural dialogue. This approach contributes to the general humanization of education, globalization and simplification of the process of exchange of knowledge and skills in all aspects of human activity, provides education with openness and mass character.

As a system of values, the axeological approach can also be viewed as a powerful motivational factor in learning. In the process of acquiring professional skills by an individual, the desire to learn the essence of the values of another ethnic group stimulates an in-depth study of didactic material, as well as an independent search for additional information, the study of the historical perspective of a particular phenomenon, which gives the individual an independently formed idea of the peculiarities of the formation of one or another professional aspect.

In the modern world, in a period of systematically increasing complexity of cultural and axiological tasks, systems of ethnic values play a key role in the process of global intercultural communication, determine the content and further development of human civilization. The synthesis of ethnic characteristics of nations entering into international contacts, as well as the construction of a unified system of human values are an essential necessity for the development and progress of mankind.

Value systems are formed, changed and rebuilt in the process of the historical development of society, absorbing certain models of socially recognized behavior. In the process of intercultural interaction, these systems can transform and even annihilate. The quantitative and qualitative interaction of different cultures directly affects the formation of common sociocultural values for actively contacting ethnic groups. Such a system of values is formed under the influence of globalization and informatization, based on public knowledge about existing nationalities and their traditions, on the experience of intercultural dialogue and understanding the difference in the cultural characteristics of its participants.

Intercultural values include primarily human or universal values, the basis of which is the biological nature of man and the basis of social contact. In different cultures, the degree of tolerance for certain phenomena is different, but the overall assessment of the phenomena is categorically the same. Such phenomena, which are similar in their assessment by society, form a system of universal human values. In modern realities, the formation of such value systems is not only inevitable, but also according to Francis Fukuyama in the modern world, where no community of people exists in isolation from others, for the peaceful coexistence of cultures, some common value system is simply necessary [4].

The formation of a unified system of values, as well as the introduction into it of the cultural values of peoples actively entering into international contacts, determines the humanization of human relations, builds a working system of international communication, 
which in turn ensures the exchange of knowledge, their widespread availability, improving the quality of professional education and its intensity.

\section{Intensification of the learning process}

In the era of total globalization, there is an urgent need to introduce fundamentally new, more effective educational models that can provide continuous multi-stage education, increase its dynamism, and provide intensive stimulation of the individual's cognitive activity. The active introduction of new technologies, means and methods, a change in the postulates of the educational process should take into account the central aspects in the ideology of globalization, namely, the system of multicultural values.

Such a collaboration of pedagogical, cultural and technological aspects will allow not only to ensure the mass character and widespread availability of education, but will also bring it to a new social level, providing a new round of development of human civilization

The intensification of the educational process together with the introduction of multicultural values will ensure the synthesis of educational models from different countries, which will entail changes in the principles of teaching, the interest of students in learning, the stimulation of continuous cognitive activity, the assimilation of old and new principles of education, which in turn solves a wide range of learning problems and expands its functional role.

An intercultural approach to the intensification of learning significantly changes the way of perceiving the reality surrounding an individual, allows one to perceive it as multipolar, use the intellectual resources of not only their own people, develop multifaceted and more intensively assimilate new information, and also stimulates the individual to use intercultural oriented technologies. In modern pedagogical realities, it is obvious that "only a developed educational system that meets the requirements of an innovative high-tech economy and is integrated into the international educational and scientific environment can become one of the most important competitive advantages of modern Russia in the global struggle for minds" [5].

In a broad sense, intensification of training is a principle of organizing a training system that makes maximum use of internal reserves to increase the effectiveness of education (https://didacts.ru/termin/intensifikacija-obuchenija.html). Coordination of this process with the cognition of intercultural values will make it possible to use not only internal, but also any reserves available to the mass user for training.

Intensification of training is an increase in the intensity of labor, an increase in the efficiency in a minimum time, an increase in the volume of material learned by an individual, as well as a greater variability of tasks. For an effective process of intensification, an optimized ratio of educational components of all aspects of speech activity, as well as improving the content of educational material, is necessary.

Rational selection of material is based on highlighting the main and additional sections, as a rule, in traditional teaching, information about the cultural and national color of the country of the target language was included in additional, secondary material, which in the overwhelming case was omitted or studied superficially. Reorganization of training taking into account intercultural aspects will allow synthesizing basic and secondary information, allowing participants in the educational process to independently isolate the elements necessary for assimilation, as well as study additional information on a given topic, using modern technologies, information teaching aids and using the skills of intercultural communication. A significant factor in the intensification of learning is the relationship between educational material and educational activity, which contributes to the development of motivation, as well as the activity and independence of the individual, contributes to the use of modern interactive learning technologies. 


\section{Possibilities of training intensification through the implementation of cultural values}

Based on the experience and knowledge of both, his own and leading specialists, the teacher chooses the objective and most applicable methods and forms of conducting the educational process for specific students. Classical methods of intensification of teaching a foreign language undergo constant and inevitable transformations under the influence of the situation in which they are applied. So the forms and methods of teaching are becoming more and more personal-oriented, individual, allowing a particular individual, independently or in a group, to maximize their potential, productively use the skills already acquired, effectively improve them and apply them in various situations of professional activity.

The existing forms of organizing classes, the purpose of which is to intensify the teaching of a foreign language, make it possible to include involvement in intercultural dialogue and a more in-depth study of its features, as well as the direct implementation of intercultural values. Knowledge, understanding and ability to appeal to intercultural values can improve collective forms of cognitive activity by organizing group work, role-playing or business play with potential opponents of intercultural dialogue. The implementation of this form of education, optimized from the point of view of multicultural communication, makes it possible to simulate the situation of professional international communication, determines multilevel immersion in the immediate language environment, and also develops the skill of individuals to choose an adequate and productive form of communication.

The integration of intercultural values into the educational process greatly simplifies the partners' perception of their opponent's picture of the world, which also makes it possible to liberate the dialogue participants, regardless of their level of training, expand the thematic base of the lesson, attract more participants in the dialogue, and help reduce the language barrier and improve the skills of all students regardless of their individual characteristics. But involving students in this process, it is necessary to teach the recipient to take the position of intercultural influence as a model, where he remains in his own cultural space, defending, approving and developing this cultural environment and at the same time joining the understanding and respect of other cultures.

Modern trends, primarily due to globalization and global informatization, as well as socio-economic, political, and other changes that lead to mass mixing of peoples, have led to a modification of the forms and methods of the traditional learning process, which in turn have become more needs-oriented of a modern individual, embraced a greater amount of information and became more individualized, since it becomes necessary for a modern person to find and establish contact not only in the business sphere of communication, but also in everyday life, family and informal associations. Accordingly, the educational process is also everywhere and certainly undergoes intensification, without which it is impossible to maintain such a fast pace of learning, which is necessary for mastering professional competence in full. The high variability of forms and methods of teaching allows you to supplement the lesson, expand it by integrating the necessary aspects of the activity into the educational process. Knowledge of intercultural values, which is essential for a productive and positive international dialogue in a dynamically developing society, is extremely necessary for such integration, and moreover, it allows solving some pressing issues of intensifying the educational process, greatly simplifying it.

Summarizing the above, we come to the conclusion that the integration of the values and cultural orientations of the people of the target language is an integral part of the process of teaching a foreign language. Language proficiency is impossible without knowledge and ability to appeal to the socio-cultural value systems of the opposing people. 
However, relying on traditional teaching methods, it becomes obvious that the practical study of this aspect has always remained superficial and secondary. The cultural aspect faded into the background, and gave way to the active study of all types of speech activity, sometimes not even letting the students understand where and when they would be able to apply their skills. The tendencies of modern education, caused by constant multicultural contacts, dictate the need to revise the traditional approaches to teaching the culture of the countries of the target language. Intercultural values should be integrated in stages, structurally, throughout the entire period of teaching a foreign language, only in this case their integration can be used as an additional method of intensifying learning.

Focusing on the acquisition and improvement of cultural knowledge in the process of education, namely the study of a foreign language, it is necessary to remember the formation of tolerant relations between representatives of different cultures, and to foster friendly relations between peoples. This is easy to do, using, in our opinion, the most productive ways of intensifying the educational process, considering which we can substantively talk about the availability of integration of intercultural values into this process, as well as the indispensable advantages of such a synthesis of educational activity.

One of the ways of intensification, which has not lost its popularity for years, is the game. This form of organization of the educational process has always been an integral part of it, even this form alone in modern realities undergoes changes dictated by the need for a reformation of education. And if earlier the game was one of the ways of knowing the peculiarities of the country of the target language in order to integrate cultural values into the learning process, now we can talk about a change in this paradigm. Intercultural values, gradually integrated into the consciousness of the student from the early stages of learning, allow expanding the subject, target and educational function of the game as a form of learning, allow you to introduce additional roles into it, as well as increase the number of participants, attracting representatives of the countries of the target language. This approach, conditioned by the well-established intercultural contact, realized in the course of the game, allows individuals to receive information in two aspects at once, didactically verified, deterministic, presented by the organizer, i.e. directly by the teacher, and disordered, due to the situation from the direct participants in the process. At the same time, the entertaining format of communication, perceived by the participants as going beyond formal training, accompanied by a high emotional background, reduces the level of stress during communication, therefore, information that exceeds the subjective barriers to assimilation of each individual can be absorbed in a more complete volume.

As a result, we come to the conclusion that intensive methods of teaching oral foreign language speech are relevant, since, on the one hand, they meet the social order and conditions of a dynamic globalizing society, on the other hand, they help to improve the indicators of oral foreign language speech of students. And since the role-playing game is multifunctional and has a sufficiently high educational potential, it will act as the main way to achieve the solution of the assigned tasks. And as already noted, role play is an effective means of intensifying oral speech, students involved in role play have the opportunity to situational use the learned phrases and expressions in practice, feel their proximity to the culture and traditions of another nation, compare and contrast intercultural values very useful for intensifying learning.

A more complex format of the lesson, acceptable for the intensification of the educational process, can be a conversation or discussion. This format is possible at more advanced levels of foreign language proficiency, allowing for intercultural dialogue on a wide range of topics. Practical experience in organizing classes of this format shows that intercultural dialogue is reduced to describing the cultural values of the nation, the characteristics of mentality, traditions and fundamental aspects of national identity. In the traditional format of such a lesson, information is exchanged without direct rethinking and 
further synthesis of cultures and the formation of cultural competence. The direct integration of cultural values into the learning process at an early stage would make it possible to modify the format of conversation and discussion, reorganize them into a more professional format of organizational activity with a wide range of topics. Individuals who already have ideas about the values of the opposing people, who are able to appeal to them, who are tolerant of the peculiarities of a foreign culture, are not limited by the framework of only a cultural dialogue about national differences. Initial knowledge of the peculiarities of the value orientations of a partner in a multicultural discussion allows you to go beyond the boundaries of a standard intercultural dialogue, to make it more professional or personoriented. Such modernization of the usual form of intensification of training allows to obtain feedback from partners of intercultural dialogue, exchange of professional and social experience, and, as a result, to motivate the participants to gradually improve their skills and abilities.

Another productive form of intensification of learning is project activity. Worldwide reforms in the field of economics, sociology and cultural studies have led to the more and more increasing popularity of this form of study, which allows the involvement of all the skills and knowledge of the individual, both in collective and individual work. International project activity in modern realities is one of the engines of progress, a way to involve young minds in science, as well as the exchange of experience between countries and generations. Ignorance of the cultural values of partners, inability to conduct an international dialogue, significantly reduces the pace of development of international projects. Gradually and structurally integrated into the consciousness of the participants' ideas about the universal human values of different peoples, the perception of the degree of tolerance towards them among the partners of intercultural dialogue allows you to skip the stage of identifying cultural and social differences of participants in project activities, and therefore increase the pace of joint professional-oriented work.

More professionally oriented forms of organizing training, such as conferences or excursions, are impossible without integrated cultural values in principle. The degree of participants' involvement in intercultural interaction determines its productivity at all stages. Thus, we can talk not only about the need for such integration, but also about its direct use with the aim of more intensifying the educational process at advanced stages of learning.

Thus, using the example of several classical forms of intensification of the educational process, we can note the wide opportunities for using intercultural values as an additional opportunity for motivation, motivation of the individual, and, accordingly, a way to increase the rate of assimilation of information and search for new ways to acquire it. The gradual introduction of intercultural values into the consciousness of students of a foreign language contributes to the systematization of ideas about the people themselves and their language, ethnic differences and ways to overcome them, and also expands the set of attitudes and beliefs inherent in each individual in favor of a more expanded system of values that organically combines established norms several cultures.

The expanded value system of an individual entering an intercultural dialogue ensures the productivity of this dialogue, helps to reduce psychological pressure, annihilate the factors that determine interethnic conflicts. It should be noted that in order to achieve the level of a developed system of intercultural values, it is necessary to integrate them at all stages of education, paying sufficient attention to the cultural aspect, to promote the study of a foreign language through the prism of not only their own culture and the culture of the country of the target language, but also by assimilating the national values of the two peoples. Only with such an approach at advanced stages of learning, allowing its intensification, intercultural values can play the role of a powerful motivator for learners. 
The integration of intercultural values into the educational process greatly simplifies the partners' perception of their opponent's picture of the world, which in turn makes it possible to liberate the dialogue participants, regardless of their level of training, expand the thematic base of the lesson, attract more participants in the dialogue, which in turn helps to reduce the language barrier and uniform improvement of the skills of all students, regardless of their individual characteristics.

Intensification of learning is an actual and promising trend of enhancing the educational process, based on the synthesis of individual psychological and collective psychological aspects, intensification allows assimilation of more new information without reducing the pace of work and the quality of education. Thus, additional intensification tools are required for the functionality of this process. Integration of intercultural values as one of the ways to intensify the educational process will provide a continuous mass exchange of experience of different nationalities and countries, will give a great stimulus to social and technical progress, and also solve many common human problems, such as political, ethnic or religious differences.

Summing up the above, it should be noted that a new form of global education, taking into account the national values of entering into international contacts, will provide a general standard of quality of professional activity, which in turn will lead to uniform social and technical progress, massive access to the existing knowledge of mankind, and also ensure equality ethnic groups at the political, cultural and social level.

\section{References}

1. M. Rostovtseva, A. Mashanov, Journal of Siberian Federal University, Humanities \& Social Sciences, 13(2), 208-218 (2020)

2. M. Kochetkov, I. Kovalevich, Journal of Siberian Federal University, Humanities \& Social Sciences, 13(2), 268-277 (2020)

3. O. Smolyaninova, D. Trufanov, Journal of Siberian Federal University, Humanities \& Social Sciences, 10(11), 1673-1698 (2018)

4. O. Smolyaninova, V. Korshunova, Science for Education Today, 9(3), 22 (2019)

5. E. Tareva, B. Tarev, Journal of Siberian Federal University, Humanities \& Social Sciences, 3(10), 432- 439 (2017)

6. O. Smolyaninova, V. Korshunova, M. Adamova, Journal of Siberian Federal University, Humanities \& Social Sciences, 10(12), 1922-1942 (2019)

7. F. Zannoni, Journal of Siberian Federal University, Humanities \& Social Sciences, 13(2), 246-257 (2020)

8. O. Smolyaninova, J. Popova, Journal of Siberian Federal University, Humanities \& Social Sciences, 12(2), 247-260 (2019)

9. O. Kozlova, U. Kozłowska, Journal of Siberian Federal University, Humanities \& Social Sciences, 13(2), 191-200 (2020)

10. O. Smolyaninova, D. Trufanov, Journal of Siberian Federal University, Humanities \& Social Sciences, 10(11), 1673-1698 (2018)

11. R. Vieira, A. Vieira, I. Vieira, C. Urbano, M. d. C. V. d. Silva, L. Baptista (Eds.), Proceedings of the international seminar and study visit ALLMEET in Lisbon'15 "Intercultural dialogue: learning, speaking, and sharing", 39-43 (2016)

12. O. Smolyaninova, EDULEARN18: Proceedings 10th International Conference on Education and New Learning Technologies, July 2nd-4th, 3862-3867 (2018) 
13. O. Smolyaninova, INTED2019; Proceedings 13th International Technology, Education and Development Conference; March 11th-13th, 1991-1997 (2019)

14 T. Tregubova, V. Kozlov, A. Kats, Journal of Siberian Federal University, Humanities \& Social Sciences, 12(2), 261-274 (2019)

15. O. Smolyaninova, S. Posokhova, M. Izotova, Journal of Siberian Federal University, Humanities \& Social Sciences, 13(2), 219-233 (2020) 